\title{
Ethical Values in the Design Concepts of Victor Papanek and Steve Jobs*
}

\author{
Olga Savvina \\ Faculty of Humanities and Social Science \\ RUDN University \\ 6 Miklukho-Maklaya Street \\ Moscow, Russia \\ E-mail: savvina_ov@rudn.university
}

\author{
Olga Maximova \\ Faculty of Humanities and Social Science \\ RUDN University \\ 6 Miklukho-Maklaya Street \\ Moscow, Russia \\ E-mail: maximova_ob@rudn.university
}

\begin{abstract}
The paper analyses ethical values of design concepts of V. Papanek and S. Jobs. Both design concepts represent the concepts that aim to change the human environment inventively and consciously in order to achieve the main aim. The simplicity and the absence of superfluous details are very important characteristics of both design concepts. The basis of consideration for V. Papanek's concept of design was taken from his book "Design for the Real World" and his other works and projects in which he had contributed. In order to reconstruct S. Jobs' understanding of design we use the interviews, his speeches, and his presentations. The values of design are self-sacrifice, the rebellion against injustice (V. Papanek) and genuine knowledge - truth that cannot be understood by everyone (S. Jobs).
\end{abstract}

Keywords —ethical values; design for value; Victor Papanek; Steve Jobs; design ethics

\section{INTRODUCTION}

Victor Papanek and Steve Jobs had different professions: Papanek was a designer and Jobs can be categorized as a talented businessman. However, they have something in common: they created not only design of devices and things, they expressed their values and their ideal world in their design. These two men gave the world values and ethical principles of design that became popular and drew the attention of the masses. Despite their target groups being so different, Papanek and Jobs had many similar views on design. Papanek hated unnecessary decoration in order to sell the product. Jobs was interested in Bauhaus that had simple lines and absence of decoration. Both designers had wider sets of interests, they were interested not only in design but also in popular cultures, cultural studies and philosophy. Papanek studied the cultural life of American Indians, Japan and other nations. Jobs was fond of Zen Buddism and Indian culture. At the same time they had opposing views on many things. V. Papanek tried to help average people, disabled children and populations of developing countries. He dreamt that technology (for example, radio) would be affordable not only for western consumers but also for all people in different regions and all social statuses. He disliked social differentiation, poverty and ecological problems and he

*The publication was prepared with the support of the "RUDN University Program 5-100" considered solving these problems as his duty. S. Jobs was working on products for people that differ from other (clever), people who were "crazy enough to move the world" ("Best marketing strategy ever! Steve Jobs Think different" 1997). It is worth noting that S. Jobs made a lot of money, while final consumers of Papanek's projects often could not pay for anything.

The aim of the study is to consider the main values of the design concepts by V. Papanek and S. Jobs. These concepts have been chosen for the study because, firstly, design for both designers does not only have aesthetic characteristics for a specific thing. Design for them is a worldview. Design reflects a way of life, inner values of the creator of things. Secondly, their concepts have been very popular in the second part of the 20th century and in the beginning of the 21 st century. Understanding of design values by V. Papanek and S. Jobs that have different target groups may give information about the reasons of their popularity, and the role of values in their popularity.

\section{MethodOLOGY}

It is worth mentioning that V. Papanek and S. Jobs have been spreading their ideas by different ways. Papanek had the opportunity to publish books and articles, express his views in academic fields and among his colleagues. Jobs could use marketing technologies and the best specialists in marketing and branding like Mike Markkula. Advertising on TV and famous directors, screen writers took part in promoting Macintosh. In general S. Jobs had more opportunities and methods of promoting his ideas and products than V. Papanek. Jobs' audience was also wider than Papanek's one.

Papanek wrote several books. The most famous his book is "Design for the real world" (first edition was published in 1971) and this work expresses his ideas quite clearly. Jobs had not written academic books or articles with explanations of his ideas, that is why we have to reconstruct his views and ideas using interviews with him and his speeches. It is very important to remember that these speeches and information given by S. Jobs could be part of the marketing. Today there are too many articles, books and dissertation works in different fields such as marketing, art and humanities and 
interdisciplinary research that are devoted to S. Jobs ideas and design concepts. This kind of material is used in the study to define Jobs' values of design.

\section{The PURPose OF THE DESIGN IN THE CONCEPTS OF V. PAPANEK}

Victor Papanek was sure design is not only the external form of a thing. Design is filled with meaning.

Victor Papanek wrote in the preface of his famous book "Design for the real world": "There are professions more harmful than industrial design, but only a very few of them" [1]. This statement shows us that industrial design for V. Papanek is not only harmful, but also very important, because useless and unconsidered activity without professional thought can be very harmful for people. There is importance and ubiquity of industrial design in this sentence, and at the same time the author argues that industrial design does not work right [2]. Papanek understands design in a broad sense: "All men are designers. All that we do, almost all the time, is design, for design is basic to all human activity" [3]. All human beings are constructing and structuralizing their environment, and designers are professionals in this field, the impact of their work is high and it has been increasing for the last decade. "The ultimate job of design is to transform man's environment and tools and, by extension, man himself" Papanek says [3]. It means that social impact of designers' work is very high and consequently the responsibility of a designer is also very high. The study of P.-P. Verbeek confirms Papanek's viewpoint [4]. The author argues that technological artifacts have moral significance and "technologies play an active role in moral action and decision-making" [5].

Victor Papanek understood all the power of design, its all-encompassing influence on people's lives and he argued that this influence had to be right and proper. His ideas have much in common with Design for Values. According to this direction in design moral control over technology must be put into effect [5] [6]. When the book "Design for the real world" was written the concept of Design for Value had not been formulated yet. So, Papanek was one of the pioneers of this kind of ideas.

The notion of VSD was formulated by Batya Friedman in 1997, but the work in this direction began in the 1960s-1970s [7]. This concept makes social and moral values central to the design and development of new technology [7] [8]. It could be said that Papanek had shared the values of VSD even before its theory was developed.

So, he considered designer's work as: 1) proactive and reflecting particular values; 2) influencing people's life and social structure, spreading the worldview of a designer. The statement of a designer's professional duty can be derived from these two considerations. The professional duty of the designer is an active work in order to solve global problems. This statement is very ambitious, but the understanding that you are doing a very important job of work gives great inspiration.
Papanek considers function as the first requirement for products of industrial designers and the first principle of professional ethics of designers. A chair should be comfortable first of all, it is not an object of art or a thing designed to show its owner's richness. Furniture, children's playgrounds, cars and other products of industrial design should be functional and safe for users. Papanek collected strange and useless things and machines "idiot-gadgets" [9], artifacts of Western consumer culture. Earlier the wellknown architect Louis Sallivan wrote that "form ever follows function. This is the law" [10]. He provided examples from nature and biology. The shape of clouds follows the wind, leaves follow their biological function, and everything is in harmony with its function. Papanek graduated from Cooper College and received a degree in architecture. It is possible that he knew about Sallivan's ideas and applied them in his design concept.

Papanek opposed cultures indigenous to the modern consumer culture that produced products to sell and satisfied "phony wants". He preferred to make functional products and solve problems of the real world. The book "How things don't work" written with the coauthor J. Hennessey illustrated the absurdity of commercial design producing "hazardous lavatory bowls" [11]. Papanek loathed status demonstrations and things which serve this aim.

The second principle of design is aesthetics that cannot exist without the context. At the same time the author of "The design for the real world" formulates the rule: if a thing is functional, it is beautiful automatically. The next rule for designers should be the following statement: things exist in the context.

The third principle helps designers to make functional products. It is usage of materials affordable on territory where final consumers live. It decreases price and problems with product delivery, making the product more affordable.

Papanek believed that "Design for Value was a feasible possibility that enabled important prospects to retain or regain moral control over technology" [12]. That is why his attitude towards the market was negative. The main goal of business is profit rather than public benefit. It was the key difference between V. Papanek and S. Jobs. The latter was conscious of western consumers' needs and tried to satisfy them.

He wrote that graduates were searching for a job with an appropriate salary in large commercial companies. The business was neither interested in moral norms and social problems of the world, nor in lives of millions of people living in poverty or problems of disabled children. Profit and consumer behavior of average Western men were much more interesting for commercial companies than real problems. Environmental crisis is also the field where design can help and solve many problems but only a few organizations were looking for designers to contribute to the innovations which would be useful in natural environment protection or wildlife management. Papanek encourages young designers to try to obey moral norms rather than follow the way commercial companies offered them and serve commercial design. If a designer decides to be moral, 
he must be strong, consistent and active. This statement also highlights the way how Papanek thought. Papanek's professional ethics is similar to the code of honor. The ideal designer for Papanek is a knight serving the design value. A designer should be ashamed of developing another "sexy toaster".

\section{THE MEANING OF DESIGN IN S. JOBS’ CONCEPT}

Steve Jobs became famous with the company he founded with his friend - Stephen Woznyak. It is worth noting that the success of Apple in the late 1970s was largely due to the computers Apple I and Apple II constructed by S. Woznyak [13]. It was only in the process of Machintosh development that S. Jobs' talents as the designer as well as the businessman were revealed. The popularity of S. Jobs culminated after the production of products - iPod, iPhone and iPad.

Since S. Jobs wrote neither books nor scientific articles devoted to design, we have to reconstruct his concept from numerous presentations, speeches, magazine articles and interviews. Firstly, he was a successful businessman and many books about him were devoted to success in business. Steve Jobs' principles or quotes about success are popular on the Internet and almost all of them show that he was very active - proactive in achieving his aims and in the embodiment of his dreams [14] [15]. In his famous speech in Stanford he said that it would be better to stay hungry, but to try to pursue one's dream [16]. This readiness to achieve the goals is similar to Papanek's willingness to help the humankind. Proactivity is a characteristic that can be applied not only to design, but it is also the beginning of value-based activity including design ethics. Proactivity establishes a serious attitude toward design.

The notion of proactivity was firstly introduced by Victor Frankl in his book "Man's Search for Meaning" (1946) [17]. Proactivity ("active life" in the original) means the possibility of a person to make decisions and take responsibility for his or her life and not and not to shift the blame on circumstances for rigours of life. It is "the opportunity to realize values in creative work". Later Steven Covey put proactivity in the first place among the habits of highly-effective people [18]. S. Jobs and V. Papanek were proactive people. They were developing and popularizing their ideas and were making other people believe them.

However, proactivity alone is not enough for a successful design concept. iPhone and iPad would not have been so popular only due S. Jobs' proactivity and his brilliant presentations. S. Jobs was familiar with Zen Buddhism and its philosophy, which rejected superfluous details and decorations of soul and man's appearance. S. Jobs was inspired by the previous ideas of design formulated in the 20 th century. S. Jobs was known to be fond of Bauhaus ideas which influenced his understanding of design. In 1981 he began to attend Design Conferences in Aspen where he studied functional design philosophy of the Bauhaus movement. Besides that, S. Jobs had preferred simplicity from an early age: "He liked the notion of simple and clean modernism produced for the masses. He also loved listening to his father describe the styling intricacies of various cars. So from the beginning at Apple, he believed that great industrial design - a colorfully simple logo, a sleek case for the Apple II-would set the company apart and make its products distinctive" [19]. Apple's first brochure contained the mantra: "Simplicity is the ultimate sophistication." S. Jobs knew that simple and functional design was the thing of the future. This concept had been already used in industrial design - in car production, machinery and engineering [20], but S. Jobs applied these ideas to Apple products - products for "the person" - the personal computer and other personal devices, such as iPod, iPad, etc.

One could say that S. Jobs shared the ideas of functional design of the Bauhaus, Sullivan's "form follows function" principle of design, value-driven design and Papanek's views concerning aversion to decorations, but he expanded the application sphere of these ideas.

When S. Jobs worked on a new computer in Next, he insisted on an opaque black one-foot cub-shaped case despite technical problems and heavy costs [21]. He followed his design principle even when his health was at stake. S. Jobs refused to use an oxygen mask because it did not correspond to his ideas of beauty. He maintained that an ugly thing could not be useful. Beautiful meant functional for S. Jobs. We can conclude that he blurred the lines between the form and the content in his design concept. It is worth noting that functional meant beautiful for Papanek, but for S. Jobs beauty was the starting point.

In order to understand beauty, we should "think different". Those who think different(ly) do not care about social status, they are better than that.

S. Jobs exaggerated ideas and transformed the reality. We know that design can differ from the content: a pretty toaster can be of low-quality and nice people can be foolish. Anyway, the appearance can tell us about the content: nice people usually go in for sports and look after their appearance which requires no less than discipline. S. Jobs exaggerated this idea claiming that design told people about the content. The claim looks absurd, but people believed S. Jobs. He was able to persuade his audience. Apple products look holistic, symbolizing beauty of form and inner beauty. Apple products were so popular that Apple's fans were seriously compared to believers [22].

\section{SimPlicity IN DESIGN CONCEPTS OF PAPNEK AND S. JOBS}

In 2005 the book "The laws of simplicity" by John Maeda came out. The author described 10 laws of simplicity that were applied in information technology, industrial design and other fields in previous years. Maeda showed many examples of gadgets and home appliances. Here is one of them: earlier tape recorders had the buttons for Rewind, Forward, Eject and nowadays we have only one button on our gadgets - Play [23]. He claims that simplicity is a modern trend in technology and many other spheres of human life nowadays. And simplicity has its own laws. Papanek's and S. Jobs' projects also followed them. 
Law 1. Reduce. Papanek and S. Jobs reduced superfluous details in their design. Constructing the radio, Papanek even reduced design including the corpus of the device. The mechanism could be put in a tin can. S. Jobs reduced all the buttons to one in iPod and iPhone.

Law 2. Organize. Papanek argued that the products were to be developed by a multidiscipline team. For example, if the team develops a new chair for secretaries, it should include secretaries, who know the aspects of enduring desk work, physicians, designers, marketing managers, familiar with company's ideology and the design concept. Finally, in order to make a "simple" thing, a complicated job should be done. S. Jobs faced the same problem. He often worked with engineers who explained to him that the desired design would contradict technical capacity. But S. Jobs insisted on his design ideas and the team had to look for solutions.

Law 3. Time. Savings in time feel like simplicity. The principle of saving materials and using materials that have been made on the territory of consumer in Papanek's "Design for the real world" reduces the time of production. One button of iPhone and its automatic switch-off reduce consumer's operations and save the time giving the opportunity to obtain the result faster. The functional design of Papanek's projects and Apple products save the time of final consumers.

Law 4. Learn. Knowledge makes everything simpler. Papanek and S. Jobs were broad-minded, their interests were cross-disciplinary. They were fond of philosophy, ecology, cultural studies and ethnology (V. Papanek), Zen Buddhism, calligraphy (S. Jobs), design theory, engineering. They always followed the news in design and technology, brought innovative ideas in design. They were never satisfied with what already had been achieved and set new goals.

Law 5. Differences. Simplicity and complexity need each other. A new "simple" shape needs a new content, new idea of a product and even new values.

Law 6. Context. What lies in the periphery of simplicity is definitely not peripheral. The example of tatami is given above: it is useless in the context of western culture, but tatami is a part of the Japanese culture and interior. Papanek paid attention to the context. It is very important in design: what is constructed, for what purposes, for whom and where. Every detail and circumstance will influence the result. S. Jobs spared no effort to develop the Apple world: iMac, iPad, iPod, iPhone, Apple store and iTunes were compatible with each other, but not with other products. He created the context, the whole world of ideal forms, the unity of technology and art, as he used to say.

Law 7. Emotion. More emotions are better than less. Papanek hated the market and the idea of production in order to sell the product without any idea how to solve real problems. He spoke and wrote openly about it. S. Jobs was a brilliant example of emotional speeches and bright presentations. Apple's slogan "Think different" is also emotional, calling to show your personal view and to challenge the public opinion.
Law 8. Trust. In simplicity we trust. Papanek solved Collingridge information problem just believing in the claim that the design could benefit the world and solve such complicated problems as social diffentiation, poverty and starvation. S. Jobs believed that an ugly thing could not be functional and refused the oxygen mask which breached the principles of "simple" design. Both designers trusted their principles of design and were sure that neglecting these principles would harm society and even health of individuals as in the example of S. Jobs.

Law 9. Failure. Some things can never be made simple. Papanek and S. Jobs never worked with luxurious products. Making luxury simple is impossible because it would not be luxury. The same is with such "simple" things as socks, needles, bread and others. Papanek and S. Jobs simplified the design of products overloaded with details: "cute toasters", children's playground in developing countries, nonfunctional chairs (Papanek), S. Jobs created iPod and iPhone with only one button, when it was not in the mainstream. Both designers simplified products with superfluous details. Moreover, they simplified the ideas of their products: Papanek claimed that they might be functional, S. Jobs made Apple products simply beautiful - truly beautiful. The latter presented the only example of a beautiful gadget. When phones and audio players were of different forms and colors for all testers, S. Jobs presented his gadget and said that it was the beauty and nothing else.

Law 10. The One. Simplicity is about subtracting the obvious and adding the meaningful. The simple radio by Papanek was the technology of the western world affordable for developing countries and poor people rather than the radio. It was social Good. iPhone and iPod were more than gadgets, they symbolized the unity of art and technology, perfect forms and perfect content.

It is worth noting that the idea of simplicity has attracted people for hundreds of years. First Greek philosophers Thales, Anaximander and Anaximenes were searching for the first principle of the cosmos [24]. Since then many philosophers and scientists have been searching for the first, simple and profound principle. Papanek and S. Jobs were also looking for this very principle in their activity and professional fields.

\section{CONCLUSION}

Summing up the comparison of the two design concepts, the common values of the concepts should be highlighted. Firstly, it is simplicity in design and following the 10 laws of simplicity in design concepts by V. Papanek and S. Jobs. Secondly, it is the "form follows function" principle of design and the close link between form and function. Thirdly, the main idea of design concepts is beyond the design. The ideas which the designers tried to express are eternal values shared by people of different cultural backgrounds.

But the key values in the design concepts of V. Papanek and S. Jobs are different. The main value of V. Papanek is solving problems of the humankind and the development of disadvantaged people. A designer must help people, especially the disadvantaged, despite the circumstances, 
market rules and personal interests. His professional duty of solving problems of "the real world" should become his main goal and his main personal interest. V. Papanek's values and aims can be compared with Prometheus myth. There are some variants of the myth, but in all of them Prometheus sacrifices himself in order to help people. Prometheus stole the fire for people and Zeus punished him, ordering Hermes to chain Prometheus to a rock forever [24]. Moreover, an eagle regularly came to peck out his liver. Prometheus was forced to endure these torments forever because he helped people - weak and mortal beings. The idea of self-sacrifice in the name of other people who are weaker and more disadvantaged can be found in religious texts, myths and legends of the peoples of the world. The most well-known and bright example is Jesus Christ, the God-man who consciously went through terrible torture in order to atone for people's sins. Despite the fact that V. Papanek was not going to die to help the people of developing countries, his image of designer reminds of the Prometheus myth. A young designer consciously refuses to share capitalistic values, to play by rules of the market, and to work for transnational companies, satisfying the "phony wants" of the western consumer. The designer chooses another way - solving problems of "the real world": helping disadvantaged people and contributing to social justice. V. Papanek accuses designers who worked for western international companies of immoral behavior. That is why the author of "Design for the real world" charmed his readers and inspired many young designers. He showed that a feat in designer profession is possible.

Another value is in the center of S. Jobs' design concept. It is the true beauty, the ideal of beauty, which cannot be understood by everyone. His products are for people who differ from the masses and rise above others. Their distinguishing characteristic is their intellect, their way of life and principles rather than money or aristocratic background. S. Jobs and his perfect taste symbolize an American dream a self-made person, achieving everything due to his or her personal characteristics, work and self-development. Apple products are not from the luxury segment. The enlightened mind of Apple consumers does not need any luxury to demonstrate their wealth, they demonstrate their perfect taste instead. Apple products help to demonstrate personal characteristics of their owner. S. Jobs plays on egoism: nobody wants to be a part of the faceless crowd in the western world today. People often believe in their uniqueness and they demonstrate it using Apple products. S. Jobs gave us the method to visualize our perfect taste and different way of thinking by buying Apple products.

\section{REFERENCES}

[1] V. Papanek, Design for the real world: Human Ecology and Social Change. London: Thames and Hadson, 1985, p. 3.

[2] O.V. Savvina, Professional Ethics of Designers in Academic Process According to V. Papanek. International Conference on Arts, Design and Contemporary Education (ICADCE 2016), pp. 476-481.

[3] V. Papanek, Design for the real world: Human Ecology and Social Change. London: Thames and Hadson, 1985, p. 3.
[4] P.-P.Verbeek, Morality in Design Design Ethics and the Morality of Technological Artifacts. In Vermaas P. E. et al. (eds.), Philosophy and Design, Springer, 2008, pp. 91-103.

[5] O.V. Savvina, Professional Ethics of Designers in Academic Process According to V. Papanek. International Conference on Arts, Design and Contemporary Education (ICADCE 2016), pp. 476-481.

[6] B. Friedman, Human values and the design of computer technology. Cambridge University Press, Cambridge, 1997.

[7] J. van den Hoven, Design for Values: An Introduction. In van den Hoven, Jeroen, Ibo Van de Poel, and Pieter E. Vermaas, eds. forthcoming. Handbook of ethics and values in technological design. Springer. 2015, pp. 1-9.

[8] V. Papanek, Design for the real world: Human Ecology and Social Change. London: Thames and Hadson, 1985.

[9] L. H. Sullivan, The tall office building artistically considered, 1896. $\begin{array}{lll}\text { Accessed } & \text { February } & 2017 .\end{array}$ https://ocw.mit.edu/courses/architecture/4-205-analysis-ofcontemporary-architecture-fall2009/readings/MIT4_205F09_Sullivan.pdf

[10] V. Papanek, Design for the real world: Human Ecology and Social Change. London: Thames and Hadson, 1985, p.79.

[11] J. van den Hoven, Design for Values: An Introduction. In van den Hoven, Jeroen, Ibo Van de Poel, and Pieter E. Vermaas, eds. forthcoming. Handbook of ethics and values in technological design. Springer. 2015, p.4.

[12] S. Woznyak and G. Smith, iWoz: Computer Geek to Cult Icon: How I Invented the Personal Computer, Co-Founded Apple, and Had Fun Doing It. NY: W.W. Norton and Compony, 2006.

[13] B. Brandal, 11 Profound Influences on Steve Jobs' Design Philosophy. Process.st. Accessed February 5, 2017. https://www.process.st/steve-jobs-design/.

[14] M. Gladwell, The tweaker. The real genius of Steve Jobs. The New $\begin{array}{llll}\text { Yorker. } & 14 & \text { November } & 2011 .\end{array}$ http://www.newyorker.com/magazine/2011/11/14/the-tweaker.

[15] S. Jobs "You've got to find what you love,' Jobs says." 2005. Stanford. Accessed February 5, 2017. http://news.stanford.edu/2005/06/14/jobs-061505/.

[16] V. E. Frankl, Man's Search for Meaning. Boston: Beacon Press, 1992.

[17] S. R.Covey, The 7 Habits of Highly Effective People, NY,1989.

[18] W. Isaacson, Steve Jobs. NY: Simon \& Schuster, 2011.

[19] P. Collopy, Economic-based distributed optimal design, AIAA Space 2001 Conference and Exposition, AIAA SPACE Forum, 2011. doi: $10.2514 / 6.2001-4675$.

[20] W. Isaacson, Steve Jobs. NY: Simon \& Schuster, 2011.

[21] Y.-C. Wu, Religious Consumption: Inside the Minds of Apple and Catholic Devotees. Texas: The University of Texas-Pan American. Jan 2015

[22] J. Maeda, The laws of simplicity. Cambridge: MIT Press, 2005.

[23] D. W. Graham, The Texts of Early Greek Philosophy: The Complete Fragments and Selected Testimonies of the Major Presocratics. 2 vols Cambridge: Cambridge University Press, 2010.

[24] E.F. Beall, Hesiod's Prometheus and Development in Myth. Journal of the History of Ideas. 52(3), 1991, pp. 355-371. 